\title{
TETANUS IN AFRICAN CHILDREN
}

\author{
BY \\ A. B. TOMPKINS \\ From the Children's Department, University College Hospital, Ibadan, Nigeria
}

(RECEIVED FOR PUBLICATION APRIL 20, 1959)

This paper is based upon part of a thesis accepted by the University of London for the M.D. degree in 1957, but it now includes the experience of the Children's Department of University College Hospital, Ibadan, Nigeria, in treating 79 children with tetanus between April, 1953, and August, 1958. Patients with neonatal tetanus are not included as they were the subject of a previous paper (Tompkins, 1958).

Publication is thought to be justified for three reasons: (1) The methods of treatment employed were simple, such as can be carried out with limited staff and equipment, so the results may be useful for comparison with those obtained by more elaborate means, such as muscle relaxants. (2) A wide range of doses of tetanus antitoxin was employed in the hope of obtaining definite information about its value in treatment. (3) The importance of the middle ear as a source of infection is stressed and the characteristic type of tetanus arising from this source is described.

\section{Site of Infection}

It was seldom possible to be certain of the site of infection owing to the high incidence of tropical ukcer, guinea-worm and infected abrasions of the legs from which few of the poorer Nigerian children are ever completely free. One patient developed post-operative tetanus after a laparotomy and in 21 patients the source of infection was thought to be the middle ear.

\section{Seasomal Incidence}

Seasonal incidence is shown in Fig. 1, prepared from the records of 77 patients admitted between August, 1953, and August, 1958. It shows the incidence to be rather lower during the wet season (June to October) than during the dry. The peak in March and the low incidence recorded for November are probably sampling errors.

\section{Mortality}

Of the 79 patients 25 died, a mortality of $31 \cdot 6^{\circ} \%$. The mortality reported by other writers is set out in Table 1.

Dietrich (1940) and Silverthorne (1947) both attributed the lower mortality among the later patients in their series to abandoning the intrathecal route of antitoxin administration, and Silverthorne also thought that the replacement of the intravenous by the intramuscular route of administration may have been a further contributory factor.

Forbes and Auld (1955) considered that the lower mortality among their patients, when compared with those previously treated in the same hospital, was due to the greater attention they paid to the maintenance of a good airway.

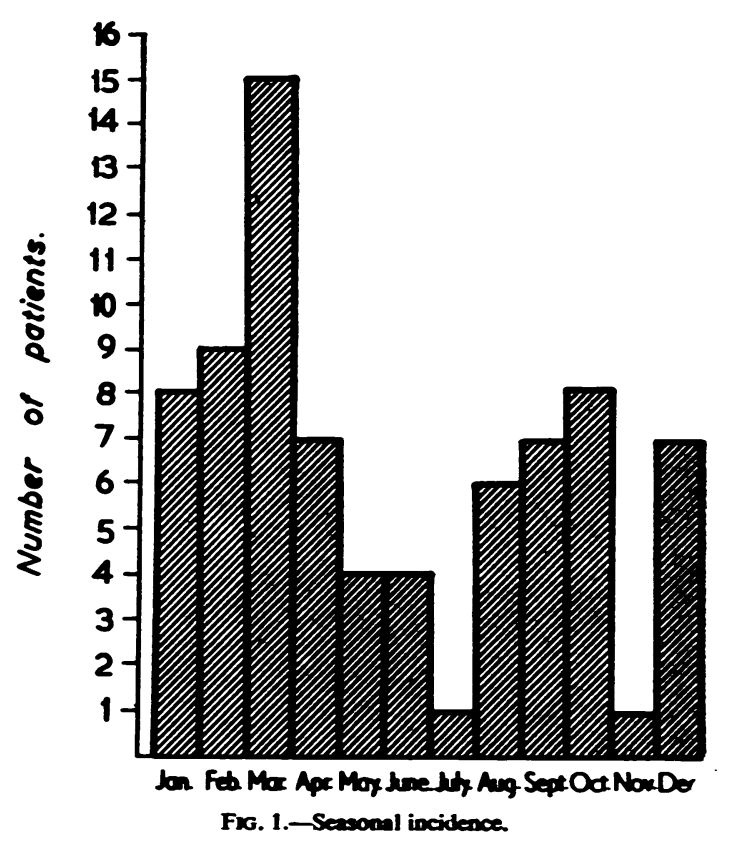


TABLE 1

MORTALITY REPORTED BY OTHER WRITERS

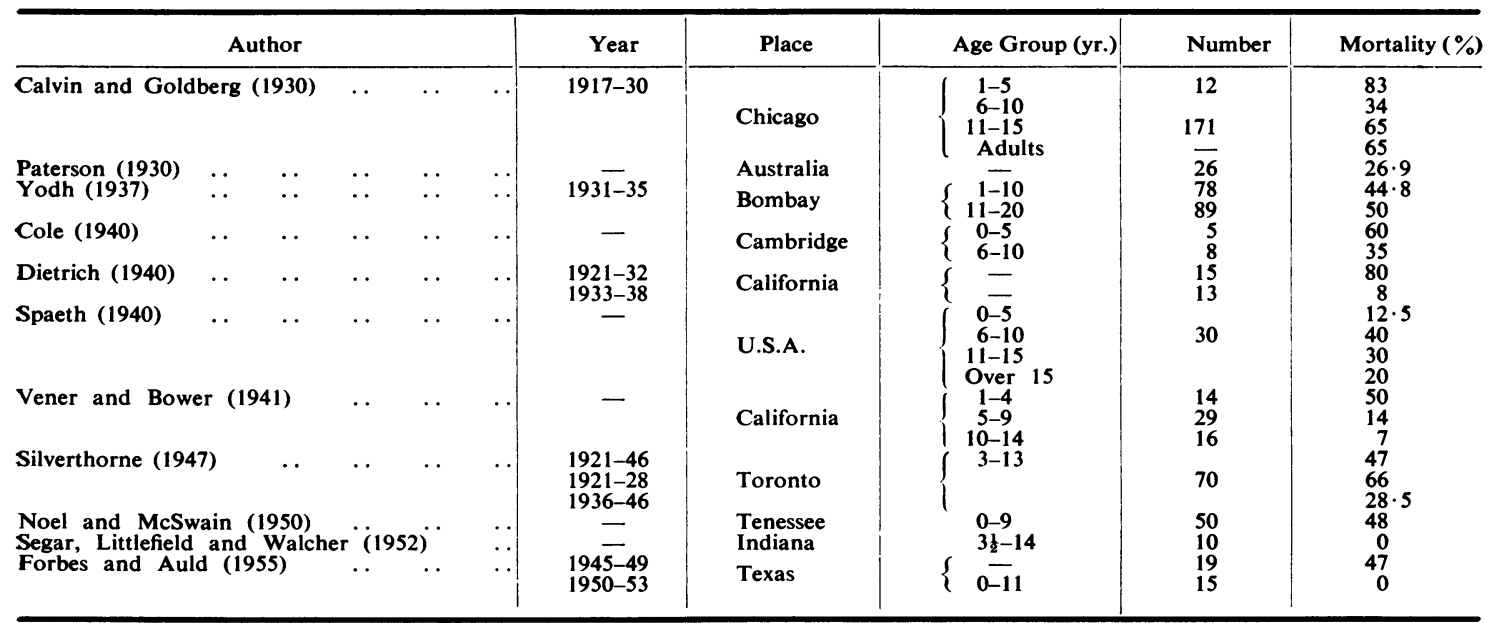

Age Incidence, and Mortality in Relation to Age. The age distribution of the patients ranged between 4 months and 13 years and is shown in Fig. 2 which

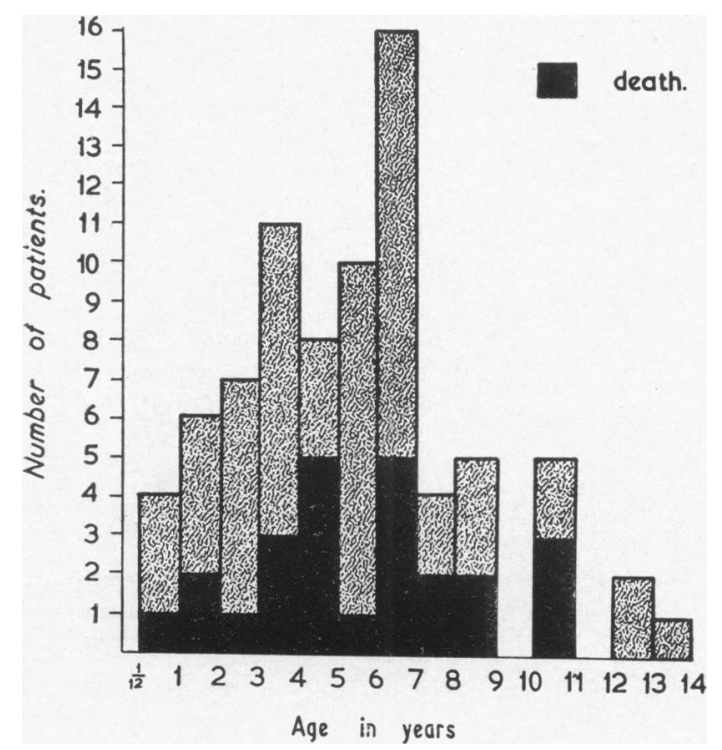

FIG. 2.-Age distribution and mortality.

also shows the percentage mortality for each age group. It shows that the incidence is highest during the middle years of childhood with a sudden decrease after the age of 7 years, though this might be due to a higher proportion of the older children being admitted to the adult wards.
Most writers consider the mortality of tetanus to be lowest during the middle years of childhood but the figures quoted in Table 1 do not give definite confirmation of this view. The present series shows a fairly uniform mortality for all ages and if a comparison is made between the mortality during the first four years of life ( 28 patients with seven deaths) and that during the second four years (38 patients with 13 deaths) $\chi^{2}$ (with Yate's correction) $=0 \cdot 28, P=0 \cdot 6$, which is not significant.

Sex Incidence. The sex incidence and the mortality in relation to it are shown in Table 2.

TABLE 2

MORTALITY IN RELATION TO SEX INCIDENCE

\begin{tabular}{|c|c|c|c|c|}
\hline & & & Male (No.) & Female (No.) \\
\hline $\begin{array}{l}\text { Patients } \\
\text { Deaths }\end{array}$ & .. & $\therefore$ & $\begin{array}{l}50 \\
13\end{array}$ & $\begin{array}{l}29 \\
12\end{array}$ \\
\hline Mortality & . & .. & $26 \%$ & $41 \cdot 4 \%$ \\
\hline
\end{tabular}

Comparing the mortality of the two sexes, $\chi^{2}$ (corrected) $=1 \cdot 36, P=0 \cdot 25$, i.e. no significant difference. Cole (1940) considered the prognosis to be better in female patients. Vener and Bower (1941) reported a mortality of $14 \%$ among boys and $37.5 \%$ among girls, but Pratt (1945), on the other hand, found the mortality among boys and girls to be $46 \%$ and $35 \%$ respectively.

Incubation Period. This could only be estimated in 22 cases. Of these the 13 patients who survived had an average incubation period of $7 \cdot 3$ days with 
a range of two to 15 days, while the nine who died had an average of 8.2 days and a range of five to 12 days.

It is generally agreed that the length of the incubation period is one of the most important factors determining the prognosis in tetanus and that the longer the incubation period the greater the chance of survival. The fact that the above figures do not conform to this principle may be due either to a sampling error or to the general inaccuracy of the uneducated African's idea of time.

In Calvin and Goldberg's (1930) series the mortality when related to incubation period was as follows: one to five days, $84 \%$; five to 10 days, $83 \%$; 10 to 14 days, $37 \%$; two to three weeks, $25 \%$; three to four weeks, $33 \%$; more than four weeks, $10 \%$.

Cole (1940) described 38 patients in whom the incubation period was known. The average incubation period of those who died was 6.5 days, and of those who recovered, 11.0 days. Only two of his patients who recovered had incubation periods of less than seven days. He stresses that the incubation period is measured from the time of infection, which is not necessarily the time of injury.

Spaeth (1940), among the patients he had treated personally, found an average incubation period of 12 days among the patients who recovered and six days for those who died.

Forbes and Auld's (1955) series of patients had an average incubation period of $9 \cdot 6$ days. All of them recovered, but of the eight patients having incubation periods of 10 days or less six were graded as severe, but the four whose incubation period exceeded 10 days included only one severe case with an incubation period of 30 days.

In the present series nine of the patients, whose incubation periods were known, were graded as severe and these had an average incubation period of 6.7 days while 11 who were graded as mild had an average of 8.6 days (two patients had to be excluded from this calculation because of insufficient information about the severity of the illness).

Onset Interval. This is the period which elapses between the appearance of the first symptoms; usually muscle stiffness, and the onset of tetanic spasms. It is of considerable prognostic importance because the mortality of tetanus has been found to vary inversely with the length of the onset interval.

Cole $(1938,1940)$ drew attention to this relationship. Among 13 patients who died he found the onset interval to be 48 hours or less in 12 and 72 hours in one, while among 16 patients who recovered the period of onset was more than
72 hours in 12, 48 hours in three and 18 hours in one. He also mentioned that in the patients who died the time of survival increased with the length of the onset interval but was never more than four times its duration.

Díaz-Rivera, Deliz and Berio-Suárez (1948) estimated the onset interval in 35 of their 59 patients. Ten patients developed convulsions on the first day of the illness with six deaths $(60 \%)$; six developed them on the second day with three deaths $(50 \%)$; three on the third day with one death $(33.3 \%)$ and 16 on the fourth day or later with no deaths.

Johnstone (1958), working with adult patients in Ibadan, found a mortality of $69 \%$ among his patients having an onset interval of 48 hours or less, and only $30 \%$ among those with an onset interval of more than 48 hours, the difference being statistically significant.

In the present series an estimate of the onset interval could be made in 18 cases. Of those patients with an onset interval of 24 hours or less, four survived and three died, while of those whose onset interval exceeded 24 hours, nine survived and two died $\left(\chi^{2}\right.$ (corrected) $=0 \cdot 36, P=0 \cdot 6$, i.e. no significant difference).

\section{Clinical Features}

As a rule the patients were not brought to hospital until the onset of spasms but they generally gave a history in which the earliest symptom was either trismus or stiffness of the neck and back. Trismus and abdominal rigidity were the most constant physical signs. The spasms did not appear to be painful.

Most of the patients were pyrexial at some stage of their illness and the relation between fever and mortality is shown in Table 3. Spaeth $(1940,1941 a, b)$

TABLE 3

MAXIMUM AND MINIMUM RECORDED TEMPERATURES AND MORTALITY BASED ON THE RECORDS OF 42 PATIENTS

\begin{tabular}{|c|c|c|c|}
\hline Temperature & $\left({ }^{\circ} \mathrm{F}.\right)$ & $\begin{array}{c}\text { Patients } \\
\text { (No.) }\end{array}$ & $\begin{array}{l}\text { Deaths } \\
\text { (No.) }\end{array}$ \\
\hline $\begin{array}{c}\text { Maximum: } \\
98-100 \\
100-102 \\
102-104 \\
\text { Over } 104\end{array}$ & $\begin{array}{l}\because \\
\because \\
\because\end{array}$ & $\begin{array}{r}15 \\
9 \\
8 \\
10\end{array}$ & $\begin{array}{l}1 \\
1 \\
5 \\
6\end{array}$ \\
\hline $\begin{array}{l}\text { Minimum: } \\
\text { Less than } 95 \\
95-96 \\
96-98 \\
98-100 \\
\text { Over } 100\end{array}$ & $\begin{array}{l}5 \\
\cdots \\
\cdots\end{array}$ & $\begin{array}{r}1 \\
20 \\
14 \\
6 \\
1\end{array}$ & $\begin{array}{l}0 \\
0 \\
6 \\
6 \\
1\end{array}$ \\
\hline
\end{tabular}

considered pyrexia to be a bad prognostic sign. In his series of patients between 1 and 15 years of age, 
no deaths occurred among the 21 patients who were consistently apyrexial. The present series does not reveal such a constant relationship but suggests, as did the temperature records of the neonatal patients, that a high minimum temperature is of more serious significance than a high maximum one.

The following case history is typical of severe tetanus with recovery.

Case 1. O.D., a male, aged 2 years, was admitted on December 15, 1953, with a history and physical signs suggesting an intussusception. A laparotomy was carried out soon after admission when the terminal ileum was found to be packed with roundworms. The bowel was opened and the worms removed.

He did not receive any prophylactic antitoxin but was given procaine penicillin 300,000 units daily. His progress was uneventful until December 26 when a nurse noticed that he was unable to open his mouth. He was immediately given 100,000 units of antitoxin intramuscularly, but next day he showed fully developed tetanus with opisthotonus and frequent severe spasms.

Fairly good control of the spasms was obtained with sodium amytal, 2 gr. intramuscularly as required, but his condition gave rise to anxiety for about a week. The last recorded spasm took place on January 7 when he received a further 20,000 units of antitoxin without ill effect.

By January 15 he was able to stand and he was discharged on January 28 with no residual signs except for some rigidity of the abdominal wall. He has been seen repeatedly since discharge and is perfectly normal.

\section{Complications}

The most important complications were respiratory obstruction and bronchopneumonia which might have been avoided in many cases had tracheotomy been carried out as recommended by recent authors (Turner and Galloway, 1949; Godman and Adriani, 1949; Creech, Woodhall and Ochsner, 1950; Biehl and Helm, 1951; Herzon, Killian and Pearlman, 1951; Segar et al., 1952; Díaz-Rivera, Trilla and Pons, 1954; Forbes and Auld, 1955).

Compression fracture of the vertebrae is a well known complication of tetanus. Dietrich (1940) encountered this in nine out of 13 patients and stressed the importance of a radiological examination of the spines of all tetanus patients before discharge. Routine radiography of the spine was not part of our practice and compression fractures were only diagnosed in two patients.

One of these patients appeared quite well on discharge from the hospital but returned to the out-patient clinic a few days later complaining of pain in the back. Radiographs then showed compression fractures of the bodies of four of the dorsal vertebrae. A radiograph of the other patient, in the absence of any symptoms, showed a series of compression fractures. He received no treatment and now appears to be perfectly normal.

Otogenous Tetanus. It is well known that the middle ear may be the site of infection in tetanus, but references to it are scattered and few writers describe more than one patient.

In 21 patients of the present series tetanus of a distinctive clinical type was associated with otitis media. In no case was full bacteriological confirmation obtained, but in 13 patients in whom bacteriological examinations were carried out the following organisms were isolated:

Escherichia coli (4); Staphylococcus saprophyticus (1); Pseudomonas (1); Proteus (1); Bacillus subtilis (3); Pleurococcus pyocyanea (4); diphtheroids (2); terminal spore-bearing Clostridia (2); other Clostridia (1). In many cases a mixed growth of organisms was obtained.

These patients presented a distinctive clinical picture in which trismus and risus sardonicus were severe in proportion to spasms and generalized rigidity which were usually mild, but two of them died. One of these had mild tetanus of the type described and died of bronchopneumonia. The other started with a mild cephalic type of tetanus but two days after admission she developed generalized severe spasms. A swab from her ear showed the presence of terminal spore-bearing Clostridia so it is likely that the ear was the true source of infection.

Case 2. S.A., a male, aged $2 \frac{1}{2}$ years, was admitted on January 4, 1954, with a five-day history of pain in the left ear and occasional muscular spasms. The day before admission the ear had begun to discharge.

On admission the child had a temperature of $99^{\circ} \mathrm{F}$. There was well marked trismus and risus sardonicus, with generalized muscular rigidity but no spasms. The tongue had been bitten slightly. There was a copious purulent discharge from the left ear. Other systems were normal. A direct smear of pus from an aural swab showed the presence of 'drumstick' bacilli morphologically resembling $\mathrm{Cl}$. tetani, but culture and virulence tests were not carried out.

He was given tetanus antitoxin 200,000 units intramuscularly on admission and procaine penicillin 600,000 units daily. After admission he began to have mild spasms for which sedation with sodium amytal, gr. 2 intramuscularly, was given as required.

The spasms ceased after two days although the trismus, risus sardonicus and muscular rigidity persisted and he used to stand all day leaning stiffly against the side of his cot. He was able to take food by mouth throughout the illness. 
He was quite well on discharge although the left otorrhoea persisted and the pus still contained tetanuslike organisnts.

Corcoran (1938) described the case of an Irish adult who showed trismus and minimum muscular rigidity associated with chronic suppurative otitis media. Cl. tetani was not isolated from the ear. The patient died of bronchopneumonia.

Stonham (1938) described a more severe case in an Indian adult who recovered, but again $\mathrm{Cl}$. tetani was not isolated from the ear.

Magarey (1947) described tetanus developing in a boy aged 9 with chronic otitis media and in this case $\mathrm{Cl}$. tetani was successfully isolated from the aural discharge. The disease was mild although general spasms occurred and the boy recovered. This case closely resembles that described above.

Rosa Febles, Ramirez, Armaiz and Torregrosa (1950) described a girl of 19 who developed mild tetanus with trismus but no spasms 16 days after an injury to her ear which caused it to discharge. Cl. tetani was present in the aural pus.

Ghosh (1950) mentioned that the ear was the source of infection in $70 \%$ of the children he treated, but did not give any details, and Khosla and Bhatt (1952), in a series of 88 Indian patients of all ages, found that in children under 4 , excluding the newly born, smallpox vaccination and the middle ear were the commonest sites of infection.

Jelnes (1955) gives the case of a 45-year-old Norwegian man who developed trismus and spasm of the left facial muscles. He had undergone a left radical mastoidectomy 20 years before with satisfactory results except for occasional slight discharge. The cavity was re-opened and necrotic material removed from which $\mathrm{Cl}$. tetani was grown. The patient never had any generalized spasms and made a good recovery.

\section{Treatment}

General. All writers recommend that tetanus patients should be nursed in a quiet, darkened room, but no such accommodation is available at the Adeoyo Hospital and the patients had to be nursed in the general children's ward. Even now, in University College Hospital, where cubicle accommodation is available, the writer prefers to keep these patients in the open ward where they can be supervised by the nurses more closely than is possible in the cubicles.

Treatment of the Wound. As the site of infection was usually unknown, no local treatment was carried out except for simple dressings to any lesion requiring them.
Authorities are divided on the question of the local treatment of the wound in cases of tetanus, some recommending wound excision, others only such treatment as appears to be necessary according to ordinary surgical standards. Creech et al. (1950) carried out excision of the wound in all cases, even when it was healed, packing it after excision with peroxide gauze. Segar et al. (1952) carried out wound debridement only when it was necessary for surgical reasons, when the area around the wound was first infiltrated with antitoxin; most other writers make similar recommendations. Forbes and Auld (1955) considered that the mortality was lower in patients whose wounds were not given any specific treatment, but this may reflect the tendency for severe wounds to be associated with a severe type of tetanus.

All these workers obtained good results, but one of Creech's six patients died, while Segar's 10 and Forbes' and Auld's 15 patients all recovered so the balance of evidence favours the view that wound excision in tetanus is unnecessary and is possibly even harmful.

Feeding. Most of the patients were able to take a liquid diet by mouth from the time of admission but some required intravenous fluids for the correction of dehydration and electrolyte imbalance.

Tube feeding after an initial trial was largely discarded as it was found to provoke spasms. Forbes and Auld (1955) abandoned it for the same reason, but during the past year, thanks to the more efficient sedation afforded by chlorpromazine and phenobarbitone, it has been used again more successfully to give a high-protein mixture composed of milk, Casilan and egg which has proved very valuable in protracted cases with inability to swallow.

Penicillin. All the patients received an aqueous suspension of procaine penicillin in doses of 300,000 to 600,000 units daily. Penicillin is now an accepted part of the treatment of tetanus but no critical assessment of its value has yet been made. Altemeier (1946), from a study of 16 patients, concluded that it was only of value in the prevention and treatment of complications, but had no effect on the course of tetanus itself. Díaz-Rivera, Ramirez, Pons and Torregrosa (1951) took swabs from the suspected sites of infection in 17 patients with tetanus. Cultures were positive for $\mathrm{Cl}$. tetani in eight of these. After the swabs had been taken penicillin treatment was started and serial cultures taken from the wounds. Cl. tetani disappeared from five of the wounds within 24 hours, from six within 48 hours and from seven within 72 hours. In only one wound 
did it persist for longer than 72 hours and from this it was eventually cleared by the use of local penicillin.

Cortisone. This was not used in the treatment of any patient in this series and has not been used at all extensively in the treatment of tetanus though Lewis, Satoskar, Joag, Dave and Patel (1954) carried out a controlled trial on two groups of 20 patients and found that the mortality was significantly lower in the cortisone-treated group. Intramuscular cortisone was thought to be harmful, but oral cortisone and hydrocortisone had beneficial effects in reducing fever and spasms.

Antitoxin. Eight of the patients received no antitoxin, the others received it in doses of 10,000 to 500,000 units. In three cases there is no record of the amount given so these have been excluded from the subsequent calculations.

The whole amount was given as a single intramuscular injection at the time of admission and only two children received extra doses later in the illness. No patient was given antitoxin intravenously or intrathecally and the intramuscular injections were given without hyalase.

Table 4 shows the results obtained with the different doses, the extra doses mentioned above being excluded.

Comparing the results obtained by giving doses of $0-20,000$ units with those obtained from doses of more than 20,000 units, $\chi^{2}=2 \cdot 6, P=1 \cdot 0$, i.e. no significant difference. If those receiving more or less than 70,000 units are similarly compared, $\chi^{2}=1 \cdot 1, P=0 \cdot 3$, again without significance.

TABLE 4

MORTALITY IN RELATION TO ANTITOXIN ADMINISTERED

\begin{tabular}{l|c|c|c|c}
\hline & \multicolumn{3}{|c}{ Units of Antitoxin } \\
\cline { 2 - 4 } & & $0-20,000$ & $20-70,000$ & Over 70,000 \\
\hline $\begin{array}{l}\text { No. of patients } \\
\text { No. of deaths }\end{array}$ & $\cdots$ & 16 & 25 & 35 \\
\hline Mortality & 7 & 8 & 8 \\
\hline
\end{tabular}

The value of antitoxin in the treatment of tetanus is still undetermined and, though many series of patients have been treated without antitoxin, the writer can find no reference to the crucial experiment now being carried out here in which a large number of patients are allocated at random into two groups, one receiving adequate doses of antitoxin and the other none, all other treatment being standardized for both groups. Such a trial is now in progress here but it will take time for a large enough series of patients to be collected to give a conclusive result. So far 44 patients have been included in the trial, 29 with neonatal tetanus and 15 older children. The results and their significance are set out in Table 5 which shows no significant difference in mortality between the group which received antitoxin and that which did not.

TABLE 5

MORTALITY FIGURES FOR 44 PATIENTS TREATED WITH AND WITHOUT ANTITOXIN

\begin{tabular}{|c|c|c|}
\hline & Antitoxin & No Antitoxin \\
\hline 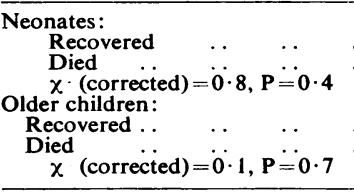 & $\begin{array}{r}4 \\
11\end{array}$ & $\begin{array}{r}1 \\
13\end{array}$ \\
\hline 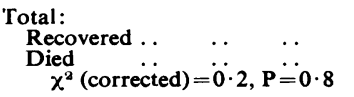 & $\begin{array}{r}6 \\
15\end{array}$ & $\begin{array}{r}6 \\
17\end{array}$ \\
\hline
\end{tabular}

Calvin and Goldberg (1930) analysed the results obtained in treating 136 patients. Of these, 26 received doses of antitoxin of 25,000 units or less with 23 deaths, and 110 patients doses of more than 25,000 units with 63 deaths $\left(\chi^{2}=8 \cdot 8, P=\right.$ less than 0.01 (present writer's calculation)). This means that there is a significant difference in favour of the group of patients who received the larger dose, but the patients received daily doses of antitoxin and, as the authors point out, those who survived would necessarily have received larger amounts of antitoxin than those who died early in the illness.

Huntington, Thompson and Gordon (1937) collected the records of 642 patients from a group of hospitals in the United States. The control group consisted of 72 patients who were treated before antitoxin was available and of these 47 died. Of the 570 patients who received antitoxin all but 228 received intrathecal antitoxin and are excluded from the present analysis. Of this antitoxin-treated group of 228 patients 142 died. Comparing the mortality in these two groups, $\chi^{2}=0.21, \quad P=0.6$ (present writer's calculation), i.e. no significant difference.

Bryant and Fairman (1940), working in the Sudan, treated 22 patients with sulphapyridine and sodium evipan and did not use antitoxin. Their mortality rate of $27 \%$ achieved under very primitive conditions compares favourably with most series treated with antitoxin.

Spaeth (1940) treated his series of patients with doses of antitoxin ranging from 11,000 to 82,000 units, the whole amount being given as a single 
intravenous injection soon after admission and after preliminary skin testing. Seven patients received doses of 20,000 units or less with one death, and 25 received more than 20,000 units with seven deaths $\left(x^{2}=0.06, P=0.80\right.$ (present writer's calculation), i.e. no significant difference).

Spaeth also collected the records of 570 patients who had received no antitoxin and of whom 462 ( $81 \%$ ) died, and compared them with 1,917 patients who had been treated with antitoxin and of whom $1,088(56 \cdot 7 \%)$ died $\left(\chi^{2}=110, P=\right.$ less than 0.01 , i.e. significantly in favour of the antitoxin-treated group).

Spaeth does not say whether the patients in his group who did not receive antitoxin were treated before antitoxin was available. Cole (1940) points out a fallacy in comparing series treated before and after the advent of antitoxin. In general, severe wounds lead to a severe form of tetanus with a high mortality. Patients with severe wounds now usually receive prophylactic antitoxin and most cases of tetanus which occur nowadays are associated with minor wounds and tend to be mild in consequence. Besides this, patients treated since the introduction of antitoxin have the advantage of many other improved methods of treatment which create a bias against the earlier group. These considerations add weight to the findings of Huntington et al. (1937), who found no significant difference in mortality in spite of these sources of bias acting against their pre-antitoxin group.

In another paper Spaeth (1941) reported the results of titrations of the antitoxin levels in the blood of 14 patients with tetanus at periods of six to 42 days after the administration of 20,000 to 100,000 units of antitoxin intravenously or intramuscularly. He concluded from his findings that from 30,000 to 50,000 units should be sufficient for routine use, but recommended 60,000 units for patients during the first five days of the illness and 40,000 units for patients with mild tetanus admitted more than five days after onset.

The best results in the treatment of tetanus in children have been those of Segar et al. (1952) and Forbes and Auld (1955) who treated 10 and 15 patients respectively without a death. Segar gave a single dose of 40,000 to 80,000 units intramuscularly after preliminary skin testing while Forbes and Auld gave from 40,000 to 340,000 units as a single dose on admission. Sensitivity tests were first carried out and the dose was given half intravenously and half intramuscularly. The total dose given was not related to the child's weight.

Sedation. The object of drug treatment in tetanus is to diminish the frequency and severity of the spasms, lessen the muscular rigidity and so prevent exhaustion. This can be done either by the use of sedatives to depress sensory excitability or by the use of muscular relaxants to prevent the excessive muscular response.

The sedatives most commonly used in the treatment of tetanus have been magnesium sulphate, now largely abandoned, chloral hydrate, the barbiturates, bromethol and paraldehyde. Recently the use of chlorpromazine has been investigated extensively (Cole and Robertson, 1955; Kelly and Laurence, 1956).

The earlier patients in the series were given sodium amylobarbitone gr. 1-3 intramuscularly as required. This was replaced later by paraldehyde given in doses of 2-6 ml. intramuscularly as often as necessary, which was thought to cause less respiratory depression then amylobarbitone. It then became the practice to give sodium phenobarbitone gr. 1-2 on admission as a basal sedative which was not repeated until two or three days later and supplemented by 2-3 ml. of paraldehyde given intramuscularly as required.

The method of sedation now employed was suggested by Dr. J. P. Puthumana (personal communication). Phenobarbitone gr. $\frac{1}{2}-1$ and chlorpromazine $12 \cdot 5-25 \mathrm{mg}$. are given every six to eight hours, by mouth if the patient can swallow or is being tube-fed, otherwise intramuscularly, with supplementary intramuscular injections of paraldehyde if required. This has been found to give better control of the spasms and less respiratory depression than any other combination of drugs.

Segar et al. (1952) treated their 10 patients with metubine iodide 1-2 mg. intramuscularly every two to three hours, giving just enough to prevent convulsions and severe spasms without abolishing rigidity, and giving supplementary sedation with barbiturates when necessary.

Forbes and Auld (1955) used thiopentone given by continuous intravenous infusion to abolish convulsions and opisthotonus but not to produce rigidity. They considered relaxation of the abdominal muscles in the presence of a cough response to tracheal suction to be the desirable level of sedation.

Tracheotomy. According to Herzon et al. (1951) this operation was first advocated for the treatment of tetanus by Thomas Curling in 1837 and first performed by G. M. Humphry in 1856 , but it did not take its place in routine treatment until recently. Most authors who have written about tetanus during the past few years stress the importance of tracheo- 
tomy as a means of maintaining a good airway in patients with respiratory difficulty (Harris, McDermott and Montreuil, 1948; Turner and Galloway, 1949; Creech et al., 1950; Herzon et al., 1951; Segar et al., 1952; Díaz Rivera et al., 1954; Forbes and Auld, 1955).

Tracheotomy was not employed in any of the patients in the present series, but considering them in retrospect the writer considers that life might have been saved in several cases had the operation been carried out.

\section{Summary}

The experience gained in treating tetanus in 79 children whose ages ranged from 4 months to 13 years is described. The total mortality was $31.6 \%$ and this was fairly uniformly distributed throughout the age groups. No significant difference in the mortality rates for the two sexes could be demonstrated.

In the sample available the average incubation period for the patients who died was found to be slightly longer than that for those who recovered, in contradiction to the generally accepted rule that the longer the incubation period the better the prognosis, but this finding is thought to be accidental. The incubation period in the mild cases was found to be slightly longer than in the severe cases, being 8.6 and 6.7 days respectively. No significant association between the onset interval and the mortality could be demonstrated.

The clinical features are described and show no unusual features, but in 21 of the patients the site of infection was thought to be the middle ear and these showed a typical mild form of the disease in which trismus and risus sardonicus were prominent but spasms and generalized rigidity slight.

No special local treatment was employed. It was usually possible to give the patients an adequate fluid diet by mouth, but tube-feeding had to be employed in some cases and parenteral fluids in others. All patients received penicillin.

Most of the patients received tetanus antitoxin in varied doses up to 500,000 units, but eight patients received none. Analysis of the results obtained does not suggest that antitoxin is of any value in treatment, but no conclusion has yet been reached.

A combination of phenobarbitone and chlorpromazine was found to be greatly superior to any other sedative.

Tracheotomy was not employed but its value in treatment is acknowledged.

My thanks are dus to Professor A. W. Woodruff, for his advice on the preparation of this paper, to Mr. D. L. N. Sly, for help with the statistics, and to Dr. R. W. F. Collis and Dr. R. G. Hendrickse, for permission to include their patients.

\section{REFERENCES}

Altemeier, W. A. (1946). J. Amer. med. Ass.. 130, 67.

Biehl, J. P. and Helm, R. A. (1951). J. Lab. clin. Med., 38, 791

Bryant, J. and Fairman, H. D. (1940). Lancet, 2, 263.

Calvin. J. K. and Goldberg, A. H. (1930). J. Amer. med. Ass., 94, 1977.

Cole, A. C. E and Robertson, D. H. H. (1955). Lancet, 2, 1063.

Cole, L. (1938). Proc. roy. Soc. Med., 31, 1205.

Cole, (1940). Lancet, 1, 164.

Corcoran, J. (1938). Brit. med. J., 1, 1004.

Creech, O., Woodhall. J. P. and Ochsner, A. (1950). Surgery, 27

Diaz-Rivera, R. S., Deliz, L. R. and Berio-Suárez, J. (1948). J. Amer, med. Ass., 138, 191.

Ramirez. E. Pons, E. R. and Torregrosa, M. V. (1951) lbid., 147, 1635 .

Trilla, F. and Pons, E. R. (1954). Ann. intern. Med., 40, 563.

Dietrich. H. F. (1940). Amer. J. Dis. Child.. 59.693.

Forbes, G. B. and Auld. M. (1955). Amer. J. Med., 18, 947

Ghosh, S. M. (1950). J. Indian med. Ass., 19, 328.

Godman, H. E. and Adriani, J. (1949). J. Amer. med. Ass., 141, 754.

Harris, R C McDermott, T. F. and Montreuil, F. i. (1948). Pediatrics, 2, 175 .

Herzon. E., Killian, E. and Peartman, S. J. (1951). A.M.A. Arch. Otolaryng., 54, 143.

Huntington, R. W., Thompson, W. R. and Gordon, H. H. (1937). Ann. Surg., 105. 93.

Jelnes, K. (1955). Acta oto-laryng. (Stockh.), 45, 398.

Johnstone. D. D. (1958). Brit. med. J., 1, 12

Kelly, R. E and Laurence. D. R. (1956). Lancet, 1, 118.

Kelly, R. E. and Laurence. D. R. (1956). Lancet, 1, 118.

Lewis, R. A., Satoskar, R. S.. Joag, G. G., Dave, B. T. and Patel, J. C. (1954). J. Amer. med. Ass., 156, 479.

Magarey, I. (1947). Clin. Rep. Adelaide Child.Hosp., 1. 39.

Noel O. F. and McSwain. B. (1950). Sth. Med. Surg., 33, 67.

Paterson, A. E. (1930). Med. J. Aust.. 1, 832.

Pratt, E. L. (1945). J. Amer. med. Ass., 129, 1243.

Puthumana, J. P. (1958). Personal ccmmunication.

Rosa Febles. C. Ramirez, E., Armaiz, G. and Torregrosa, M. V. (1950). Bol. Asoc. méd. P. Rico, 42. 243.

Segar, W. E., Littlefield, P. A. and Wakher, D. N. (1952). J. Pediat., 40,772 .

Silverthorne, N. (1947). Ibid.. 30. 195

Spaeth, R. (1940). Amer. J. Dis. Child., 60, 130.

— (1941a). Ibid., 61, 1146. (1941b). Irch intern. Med 68, 1133.

Stonham F. V. (1938). Brit. med. J., 1, 386.

Stonham, F. V. (1938). Brit. med. J., 1,
Tompkins, A. B. (1958). Ibid., 1, 1382 .

Turner, V. C. and Galloway, T. C. (1949). Arch. Surg. (Chicago), 58, 478.

Vener, H. I. and Bower, A. G. (1941). J. Amer. med. Ass., 116, 1627.

Yodh, B. B. (1937). Brit. Med. J. 1. 855. 